\title{
Studies on design of heterogeneous catalysts for biodiesel production
}

\begin{abstract}
The production of biodiesel is gaining momentum with the ever increasing demand of the fuel. Presently, limited literature is available with respect to well designed solid heterogeneous catalyst for biodiesel production considering all the characteristics, process and operation parameters. Hence, a study was conducted to design effective heterogeneous catalyst for biodiesel production. Further, the significant impact of different catalysts, different feed stock, various reaction conditions such as temperature, methanol oil molar ratio, catalyst concentrations and stability/inactivation of the catalysts, are detailed out for transesterification process of biodiesel production. Based on the studies it can be concluded that well designed heterogeneous catalyst can yield high throughput of biodiesel.
\end{abstract}

Keyword: Biodiesel; Transesterification; Heterogeneous catalyst; Feed stock. 